\title{
OPTICAL, ELECTRICAL AND PHOTOELECTRICAL PROPERTIES OF QUERCETIN- CO(II) COMPLEX/N-SI ORGANIC-INORGANIC HYBRID DEVICE
}

\section{Cihat Özaydin ${ }^{* 1}$, Ahmet Tombak ${ }^{2}$, Mehmet Boğa $^{3}$, Tahsin Kiliçoğlu ${ }^{4}$}

${ }^{* 1}$ Depart. Of Computer Engineering, Faculty of Engineering and Architecture, Batman University, Batman, 72000, Turkey

${ }^{2}$ Depart. Of Physics, Faculty of Art\&Science, Batman University, Batman 72000, Turkey

${ }^{3}$ Depart. Of Pharmaceutical Technology, Faculty of Pharmacy, Dicle University, Diyarbakir 21280, Turkey

${ }^{4}$ Depart. Of Physics, Faculty of Science, Dicle University, Diyarbakir 21280, Turkey

*cihat.ozaydin@batman.edu.tr

Quercetin is a member of the flavonoid's class and colorful organic molecule widely distributed in nature. Quercetin is known as 2-(3,4-dihydroxyphenyl)3,5,7-trihydroxy-4H-chromen-4-one with molecular formula C15H10O7. Also, quercetin has conjugated structure with $16 \pi$-rich electrons. In this study, Quercetin cobalt (II) complex (Quercetin-Co(II) Complex) was synthesized. The thin films of synthesized quercetin cobalt (II) complex were formed on glass and semiconductor substrates by sol-gel spin coating technique. The absorption, reflection and transmittance spectra of the thin film were taken in 200-1100 $\mathrm{nm}$ wavelength range. The optical band gap of the film was determined from absorption studies and was found to be $2.59 \mathrm{eV}$ for direct transitions and $1.90 \mathrm{eV}$ for indirect transitions. The morphological properties of the thin film formed on the semiconductor substrates was analyzed by scanning electron microscopy (SEM) and atomic force microscopy (AFM). We fabricated Au/Quercetin-Co(II) Complex/n-Si organic-inorganic hybrid device to investigate electrical and photoelectrical properties. The current-voltage (I-V) measurement of the device was carried out at room temperature and in dark. The device has a rectification behavior with the ideality factor $n$ of 1.55 and the barrier height $\phi b$ of $0.77 \mathrm{eV}$. In addition, the short circuit current (Isc) and open circuit voltage (Voc) have been extracted from the I-V measurements under $100 \mathrm{~mW} / \mathrm{cm} 2$ illumination conditions. Besides, the capacitance-voltage $(C-V)$ characteristics of the device at different frequency and room temperature are discussed. 
Key words: Quercetin-co(II) complex, Thin film, Optical properties,

Photoelectrical properties

\section{Introduction}

Conjugated organic materials have been attracted attention for decades. They have been used in optoelectronic industry owing to their low cost, can be coated large areas and easy to synthesis. By making contact them with inorganic semiconductors, i.e. $\mathrm{Si}, \mathrm{GaAs}, \mathrm{GaN}$ and so on, many electronic and optoelectronic devices, OLEDs[1-4], Schottky Barrier Diodes (SBD) [5-7], OFETs[8-10]have been fabricating for long years. OLEDs have been extensively studied because of a large number of touchscreen mobile phone and thin displays fabrications. There have been variety of research on organic-inorganic (OI) structures while fabrication of nanoscale devices. It is advantageous to use inorganic semiconductors with high mobility and organic material as active layer for producing low operating voltage devices. Besides, with the help of large area and pretty low cost fabricating techniques organic materials can be coated onto inorganic semiconductors or any other[11-12]. By changing thickness or chemical bonding of organic material one can optimize electronic and optical properties of OI contacts. Junction quality of OI contacts can be determined by barrier height (BH) and ideality factor (n). BH can be tuned by proper organic material. Ideality factor is strongly related to thermionic emission model, therefore, electrical properties of OI contact can be controlled by organic interlayer. Some researchers[13] showed that by inserting an organic layer BH lowers and diode deviates from ideality.

In this study, we synthesized quercetin-co(II) complex according to the literature[14]. Chemical structure of the quercetin-co(II) complex is shown in Fig. 1. The thin films of synthesized quercetinco(II) complex were formed on glass and semiconductor substrates by sol-gel spin coating technique. Our aim is to investigate optical, electrical and structural properties of spin coated quercetin-co(II) complex thin film for suitability and possibility of electronic and optoelectronic devices applications. The absorbance, reflectance and transmittance spectra of the thin film were taken in 200-1100 nm wavelength range. The optical band gap of the film was determined from absorption studies. The morphological properties of the thin film formed on the semiconductor substrates was analyzed by scanning electron microscopy (SEM) and atomic force microscopy (AFM). We fabricated $\mathrm{Au} /$ Quercetin-co(II) complex/n-Si organic-inorganic hybrid device to investigate electrical and photoelectrical properties. The current-voltage (I-V) measurement of the device was carried out at room temperature and in dark. In addition, photoelectrical properties of Au/Quercetin-co(II) complex/n-Si hybrid diodes were studied under light illumination conditions. Besides, the capacitance-voltage $(\mathrm{C}-\mathrm{V})$ characteristics of the device at different frequency and room temperature were discussed. 


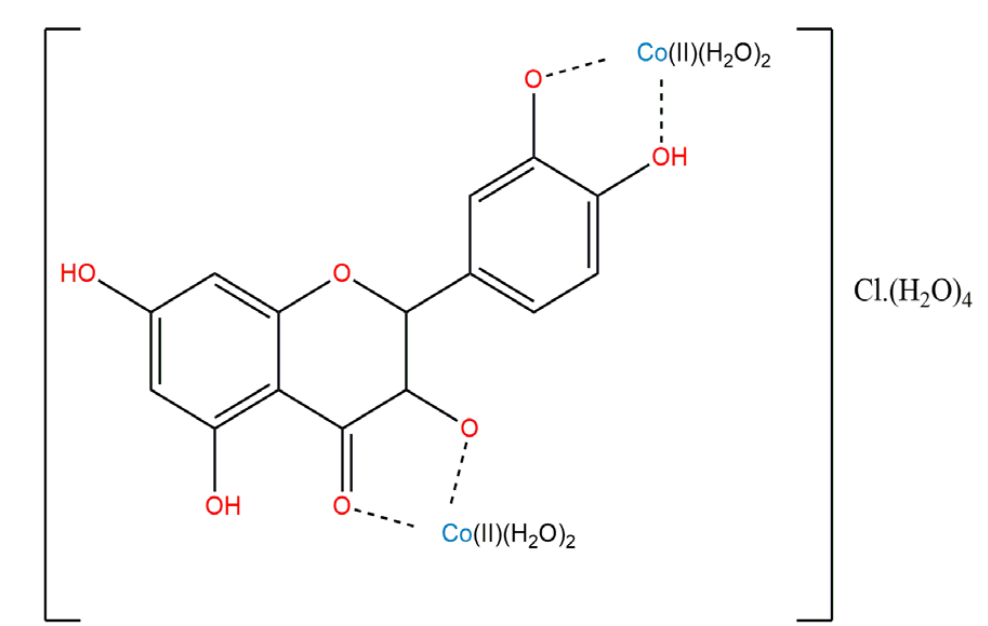

Figure 1. Chemical structure of the Quercetin-co(II) complex

\section{Methods}

In this work n-type $\mathrm{Si}$ wafer with $1-10 \Omega \cdot \mathrm{cm}$ resistivity for electronic properties and soda lime glass (SLG) for optical measurement were used. SLGs were ultrasonically cleaned with acetone, ethanol and DI water to get rid of organic contaminations. As-bought wafer was boiled in trichloroethylene for 5 minutes. After rinsing with deionized water $(18 \mathrm{M} \Omega)$, the wafer was applied ultrasonication in acetone and ethanol for 5 minutes. Si wafer was immersed in HF:H2O (1:10) for $30 \mathrm{sec}$. to remove natural oxide layer. In order not allow oxidation, the wafer was mounted to sample holder in the vacuum chamber without waiting. At 10-6 Torr vacuum level, high purity gold (99.99\%) was evaporated onto unpolished side of the wafer. Quercetin-co(II) complex was dissolved in methanol and the mixture was stirred 1 hour to obtain homogenous solution at room temperature. The wafer piece was mounted into spin coater and the solution was dropped in every step of rotation with small dropwise. The solvent evaporated after a few minutes waiting. High purity gold metal was thermally evaporated onto Au/Quercetin-co(II) complex coated n-Si wafer by shadow mask. Microstructural and morphological properties of the $\mathrm{Au} /$ Quercetin-co(II) complex film deposited on n-Si substrate were determined by Fei Quanta FEG 250 Scanning Electron Microscopy (SEM) and Park System XE 100 AFM imaging systems. Surface of the organic film was photographed by FEI FEG Quanta 250 scanning electron microscope. Current-voltage (I-V) and capacitance-voltage (C-V) measurements were conducted in dark by Keithley SCS 4200 sourcemeter. In order to investigate light response of the structure I-V measurement were repeated under the illumination of $100 \mathrm{~mW} / \mathrm{cm} 2$ light intensity by solar simulator with AM1.5 global filter. 
Incident light

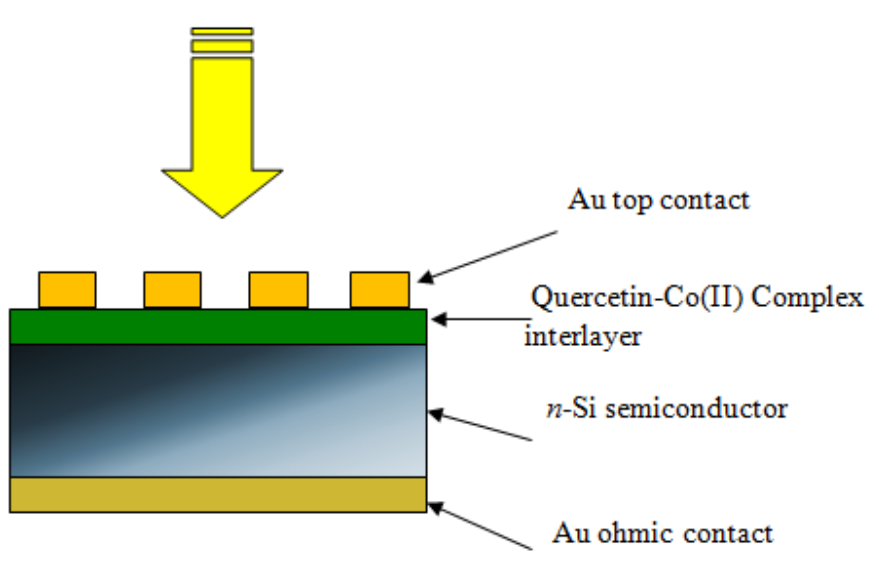

Figure 2. Shematic diagram of n-Si/Quercetin Co(II) complex/Au diode

\section{Results And Findings}

\subsection{Optical and Morphological Properties of the Film}

The variation of absorbance, transmitance and reflectance spectra of quercetin-co(II) complex thin film grown on the glass by spin coating technique is shown in Figure 3a. The optical absorption spectrum was measured with the wavelength between 300 and $1100 \mathrm{~nm}$. To determine the optical band gap we plotted photon energy (ahn) 2 versus (hn) and (ahn)1/2 versus (hn) graphs. It is understood from the graphs of quercetin-co complex is a direct optical band gap. From the extrapolation of the linear portion of the plot, quercetin-co(II) complex has a band gap value of $2.59 \mathrm{eV}$. The optical band gap of thin film was calculated by using the following equation[15];

$$
\alpha=\frac{C\left(h v-E_{g}\right)^{m}}{h v}
$$

where $\mathrm{C}$ is an energy-independent constant, Eg is optical band gap, hv is the energy of the incident light. In this equation, $m$ is the constant which determine type of optical transition. It takes the value $1 / 2$ for direct allowed transitions and it takes the value 2 for indirect allowed transitions. 


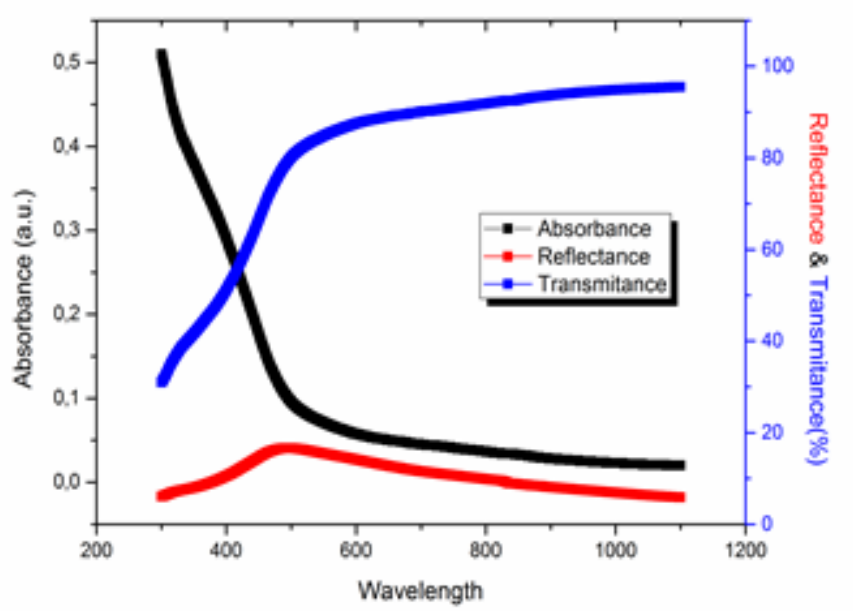

Figure 3a. Absorbance, Transmitance and Reflectance spectra of Quercetin-co(II) complex thin

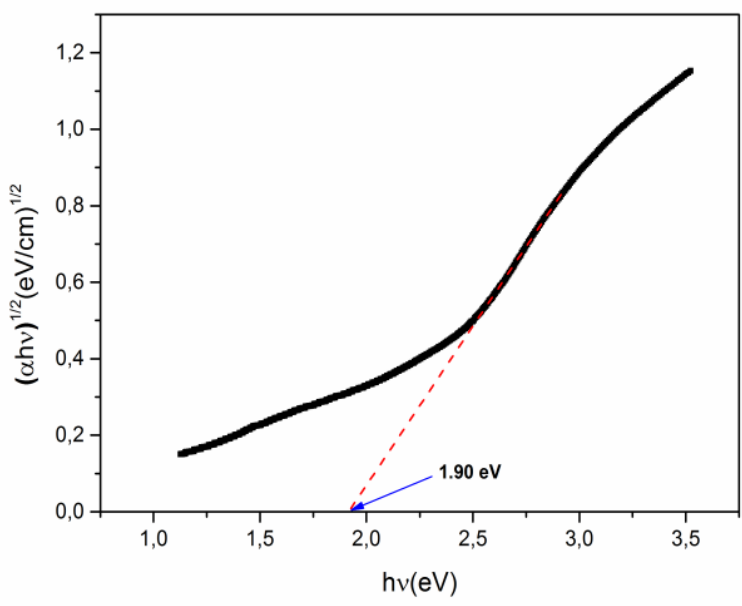

Figure 3b. Tauc's plot of Quercetin-co(II) complex thin films for indirect allowed optical band

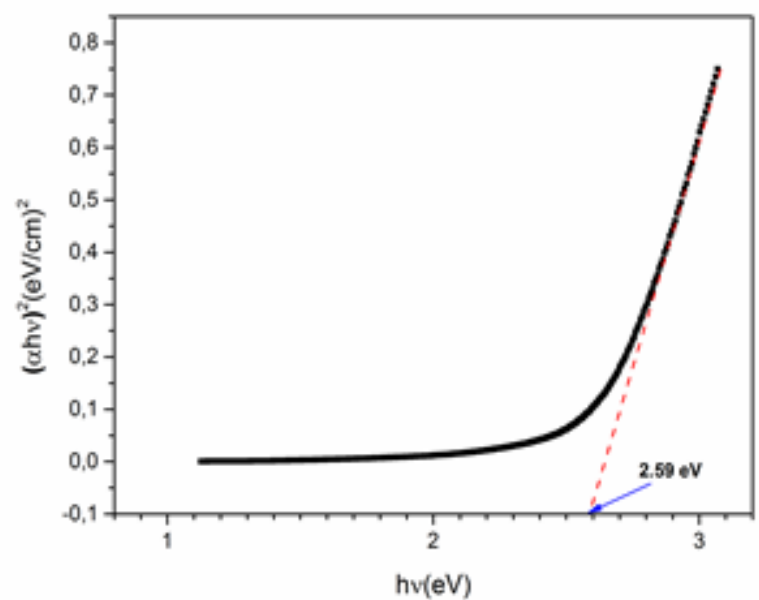

Figure 3c. Tauc's plot of Quercetin-co(II) complex thin films for direct allowed optical band gap 
The surface morphologies of the quercetin-co(II) complex thin film on n-Si wafer were displayed in SEM and AFM images (Figures 4 and 5). Figure 4 shows the SEM picture of the film coating surface on $\mathrm{Si}$ wafer. The surface morphology of quercetin-co(II) complex coating prepared on a Si wafer is rather rough, and we did not observe clusters of any definite shape or size for this coating. We see a number of randomly-shaped features of the size of few hundred nanometers, randomly distributed on the coating surface. In order to support SEM results and investigate surface roughness of the films, AFM analyses were applied. AFM results were depicted in Figure 5 for the quercetin-co(II) complex film. The data can also be displayed as a $3 \mathrm{D}$ plot. One interesting point to note that the figure 5 is the height image of the film surface which shows only the height contrast of the surface feature by the color map. The surface morphology of the quercetin-co(II) complex film formed from clusters with random orientation shows in the rough topography that confirms the formation of film with quercetin-co(II) complex molecules. AFM image of the film represents nanoscale surface roughness between few hundred nanometers.

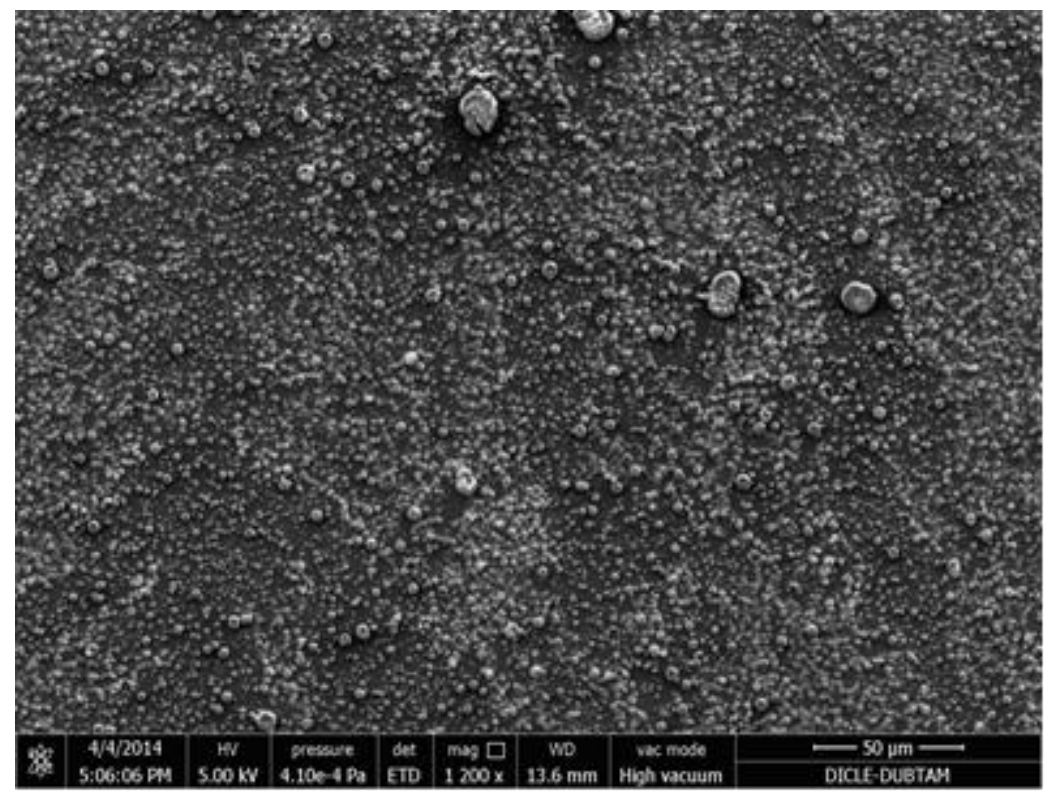

Figure 4. The SEM picture of the Quercetin -co(II) complex coating surface on Si wafer

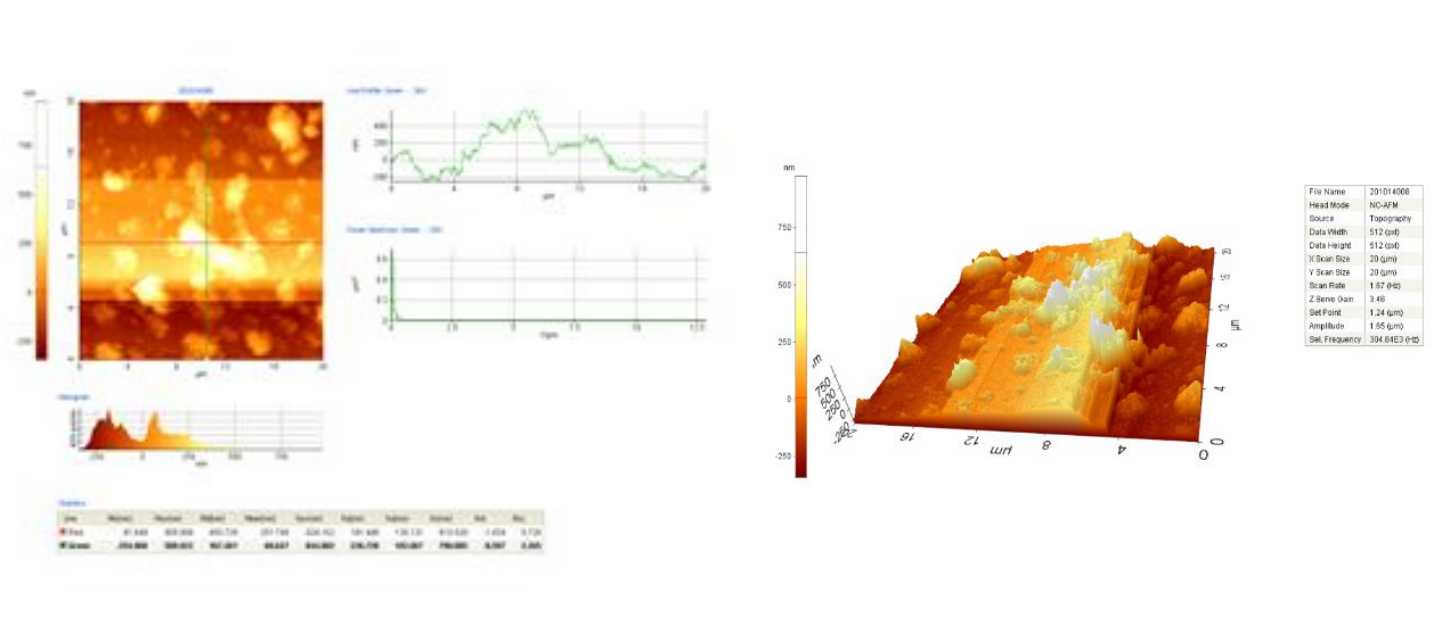

Figure 5. The AFM picture of the Quercetin-co(II) complex coating surface on Si wafer 


\subsection{Electrical and Photoelectrical Properties of Au/Quercetin-Co(II)/n-Si Diode}

The electrical characteristics of Au/Quercetin-co(II) complex/n-Si heterojunction diode were investigated by current data obtained from voltage between $-2 \mathrm{~V}$ and $2 \mathrm{~V}$ in dark at room temperature. Figure 6. exhibits semi logarithmic I-V characteristics of Au/Quercetin- co(II) complex/n-Si diode measured in dark at room temperature. The rectification ratio has a factor of 4000 approximately achieved between the forward and reverse bias current at $\pm 1 \mathrm{~V}$, and the diode shows good rectification behavior. In Schottky type diodes, current obey thermionic emission (TE) theory of which flow of charge carriers is induced by temperature. Although Au/Quercetin-co complex/n-Si is not exactly Schottky type, the hybrid diode behaves like an MS junction at the intermediate forward bias voltage. The net current through the junction induced by temperature under certain applied voltage was expressed as.

$$
I=I_{0}\left[\exp \left(\frac{q V}{n k T}\right)-1\right]
$$

where, $\mathrm{q}$ electron charge, $\mathrm{k}$ Boltzmann constant, $\mathrm{T}$ absolute temperature and $\mathrm{n}$ ideality which indicates distribution of barrier height $(\mathrm{BH})$ homogeneity. $\mathrm{I} 0$ is saturation current and can be deduced from linear portion of the semi-log I-V plot and varies with temperature.

$$
I_{0}=S A^{*} T^{2} \exp \left(-\frac{q \Phi_{b}}{k T}\right)
$$

where $\mathrm{S}$ is effective diode area, $\mathrm{A} *$ is Richardson constant equals to $110 \mathrm{~A} / \mathrm{cm} 2 \mathrm{~K} 2$ for $\mathrm{n}-\mathrm{Si}$ (Sze \& $\mathrm{Ng}$, 2007). $\Phi b$ is zero bias barrier height. Ideality factor at relatively high voltages can be extracted as follows;

$$
n=\frac{q}{k T}\left(\frac{d V}{d \ln I}\right)
$$

By combining Eq. 2 and Eq. 4, $\Phi \mathrm{b}$ and ideality factor values of the Au/Quercetin-Co(II) Complex/n-Si hybrid diode were calculated as b $0.77 \mathrm{eV}$ and 1.55 respectively. The obtained ideality factor of the diode is higher than unity. This indicates that the diode exhibits a non-ideal diode behavior which can be attributed to voltage drop through the junction, unavoidable oxide layer, high interface states and series resistance (RS). The value of $\Phi b$ higher than that of conventional Au/n-si diodes[16-18]. It is concluded that barrier height formed in the Au/n-Si junction can be modified by organic interlayer. In other words, charge transport mechanism in MS interface can be controlled by an organic interlayer. However, obtained barrier height value of the diode is acceptable among similar Au/organic/n-si diodes.

The high ideality factor value and downward concave curvature of the forward bias I-V plot at relatively higher applied voltage indicate that the series resistance effect plays important role in determining the performance of the decice. Because, series resistance dominates the voltage drop through the semiconductor-organic interface. To estimate the series resistance and barrier height of diodes Norde proposed a modified current-voltage equation[17] by taking series resistance into account as follows $F(V)=\frac{V}{\gamma}-\frac{k T}{q} \ln \left(\frac{I(V)}{S A^{*} T^{2}}\right)$ 
where $\gamma$ is the first integer (dimensionless) greater than $\mathrm{n} . \mathrm{I}(\mathrm{V})$ is current obtained from the $\mathrm{I}-\mathrm{V}$ curve. $\mathrm{F}(\mathrm{V})$ vs. V plot is given in figure 7. Once the minimum of the F vs. V plot is determined, the value of barrier height can be obtained from Eq. (6), where $F(V 0)$ is the minimum point of $F(V)$ and $\mathrm{V} 0$ is the corresponding voltage. Barrier height was found to be $0.84 \mathrm{eV}$ and, by using Norde's method, the value of series resistance was obtained as $914 \Omega$.

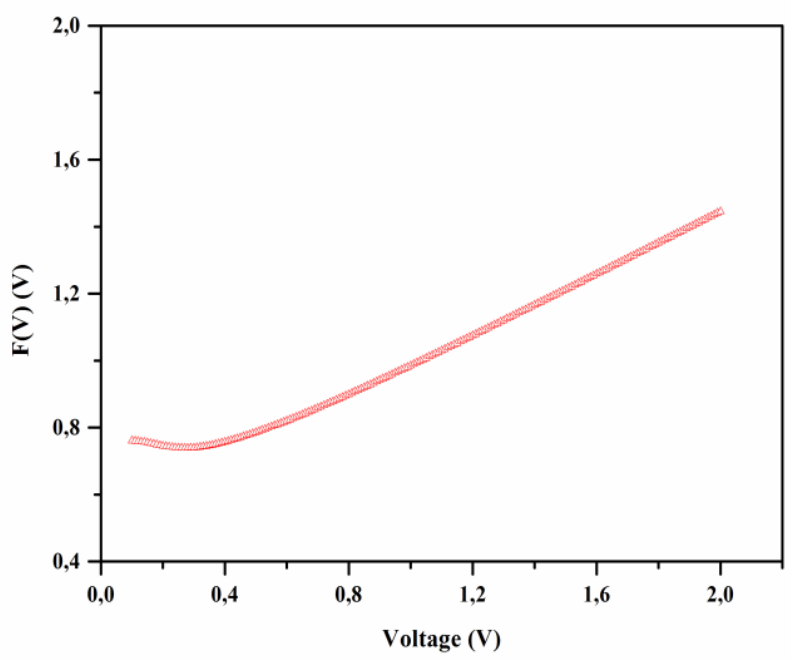

Figure 7. F(V) vs. V plot of Au/Quercetin-co(II) complex/n-Si diode

$\Phi_{b}=F\left(V_{0}\right)+\frac{V_{0}}{\gamma}-\frac{k T}{q}$

$R_{s}=\frac{k T(\gamma-n)}{q I}$

The capacitance-voltage $(\mathrm{C}-\mathrm{V})$ measurement is one of the most popular electrical measurement techniques used to characterize a Schottky diode. Generally, the capacitance measured in the Schottky diode depends on the reverse bias voltage and frequency. Its voltage and frequency dependence originates from the particular features of the Schottky barrier, impurity level, high series resistance, interface states and interface layer between the organic layer and p-Si substrate, etc. In Schottky structures, the diode capacitance can be written as [19]:

$\frac{1}{C^{2}}=\frac{2\left(V_{d}+V\right)}{q \varepsilon_{s} S^{2} N_{d}}$

where $\varepsilon s$ is the dielectric constant of $\mathrm{n}-\mathrm{Si}, \mathrm{Vd}$ is the diffusion potential at zero bias and is determined from the extrapolation of the linear $\mathrm{C}-2-\mathrm{V}$ plot to the $\mathrm{V}$ axis[20]. The value of barrier height can be calculated by the relation:

$\Phi_{b}(C-V)=V_{d}+V_{n}$ 
where $\mathrm{Vn}$ is the potential difference between the Fermi level and the bottom of the conduction band of $\mathrm{n}-\mathrm{Si}$ and can be calculated by knowing the carrier concentration $\mathrm{Nd}$ and it is obtained from the following relation

$$
V_{n}=\frac{k T}{q} \ln \left(\frac{N_{c}}{N_{d}}\right)
$$

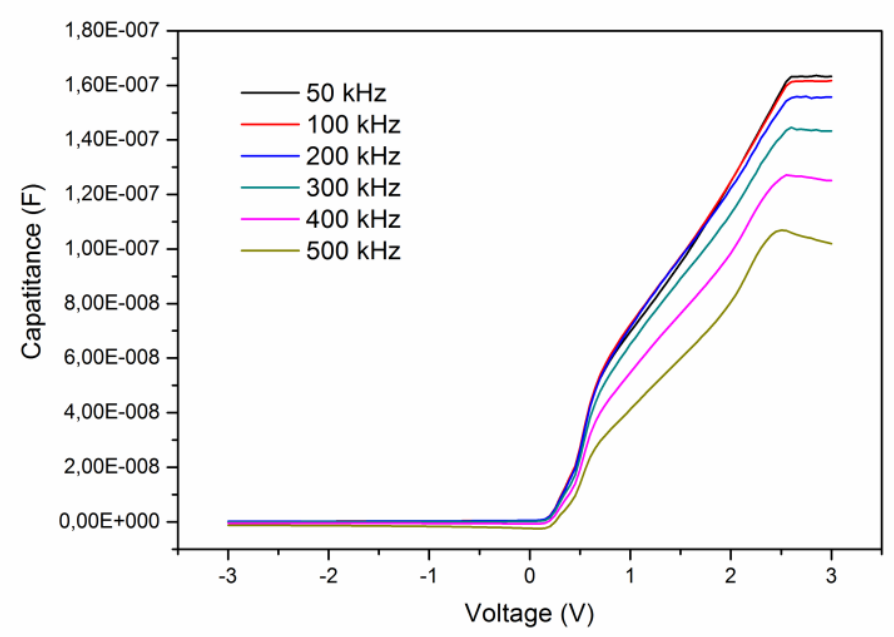

Figure 8. C-V characteristics of Au/Quercetin-co(II) complex/n-Si

where $\mathrm{Nc}=2.8 .1019 \mathrm{~cm}-3$ is the density of effective states in the conduction band [4]. Figure 8. shows (50-500 kHz) C-V characteristic of the Au/Quercetin-co(II) complex/n-Si MIS capacitor with a gate bias sweep from +3 to $-3 \mathrm{~V}$ at room temperature. From the slope and voltage axis intersect of $\mathrm{C}-2-\mathrm{V}$ plot shown in Figure 9. by using $\mathrm{C}-\mathrm{V}$ data, diffusion potential, barrier height and free carrier dopant density have been calculated as $0.585 \mathrm{~V}, 0.80 \mathrm{eV}$ and $6.53 \times 1015 \mathrm{~cm}-3$, respectively. It can be seen that the barrier height obtained from $\mathrm{C}-\mathrm{V}$ measurement approximately agrees with that obtained from $\mathrm{I}-\mathrm{V}$ and Norde's method. 


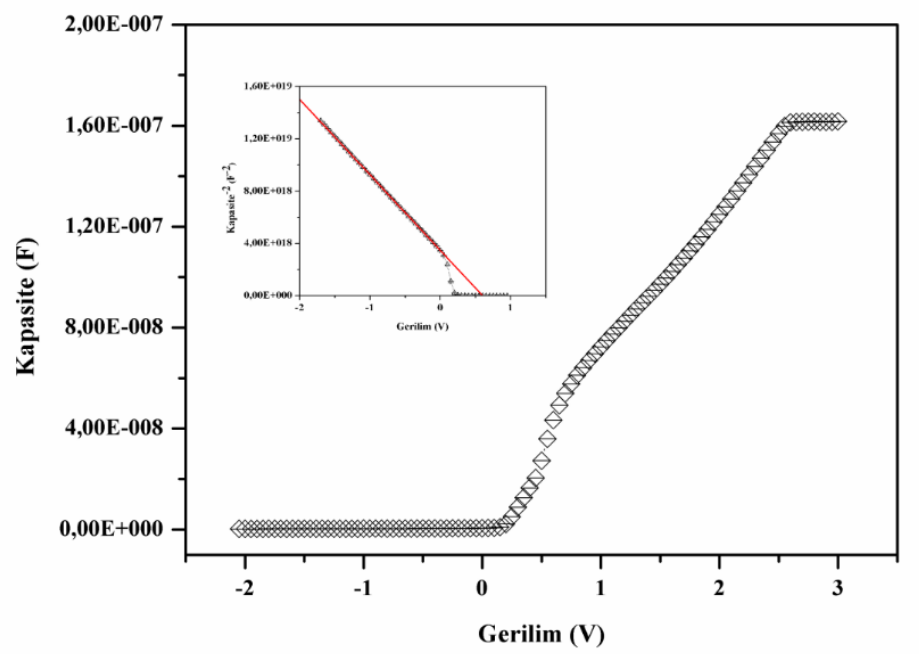

Figure 9. C-2-V plot of Au/Quercetin-co(II) complex/n-Si

The effect of white light on the Au/Quercetin-Co(II) complex/n-Si diode is shown in Fig. 10. The reverse current increases by almost three orders when white light is incident on the device. The short circuit current (Isc) and open circuit voltage (Voc) values for the device have been extracted as 2.3x10-5 A and $0.17 \mathrm{~V}$, respectively.

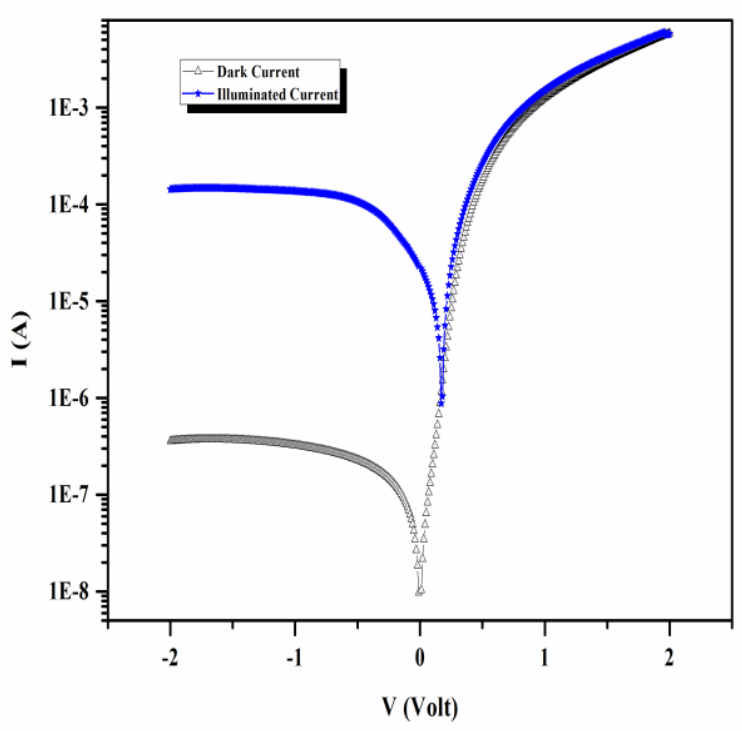

Figure 10. Current-Voltage plot of Au/Quercetin-co(II) complex/n-Si under illumination 


\section{Conclusion}

Quercetin-co(II) complex thin films were deposited onto glass and n-typre Si. The optical properties of the films have been studied in the spectral range 200-1100 $\mathrm{nm}$. The absorbance, reflectance and transmittance spectra of the thin films were taken. Thin film has an absorption edge at around $500 \mathrm{~nm}$ wavelength. Optical absorption studies in 200-1100 nm wavelength range at room temperature showed thin films optical band gaps in the $2.59 \mathrm{eV}$ range for direct transitions and $1.90 \mathrm{eV}$ for indirect transitions. The electrical and photoelectrical properties of Au/Queretin-co(II) complex/n-Si organic-inorganic hybrid diode have been investigated by using current-voltage characteristics. The ideality factor and barrier height of the diode were determined as 1.55 and $0.77 \mathrm{eV}$, respectively. By using Norde's function , series resistance and barrier height were determined as $914 \Omega$ and $0.84 \mathrm{eV}$, respectively. Under 1.5 AM illumination, the diode showed photovoltaic properties together with $\mathrm{Isc}=2.3 \times 10-5 \mathrm{~A}$ and $\mathrm{Voc}=0.17$ $\mathrm{V}$ values. Also, the $\mathrm{C}-\mathrm{V}$ measurements of the diode were performed at different frequency and room temperature. From the analysis of the $\mathrm{C}-\mathrm{V}$ measurements diffusion potential, barrier height and free carrier dopant density were calculated as $0.585 \mathrm{~V}, 0.80 \mathrm{eV}$ and $6.53 \times 1015 \mathrm{~cm}-3$, respectively. The obtained results proved that the Au/Queretin-co(II) complex/n-Si diode can be used as photodiode or photo sensor in optoelectronic applications. 


\section{References}

[1] Ahn, K.-H., Ryu, G. Y., Youn, S.-W., \& Shin, D.-M. (2004). The conjugation effects on the luminescence properties of oligophenylenes for the OLED. Materials Science and Engineering: C, 24(1-2), 163-165. doi:http://dx.doi.org/10.1016/j.msec.2003.09.010

[2] Bukhari, S. B., Memon, S., Tahir, M. M., Bhanger, M.I. (2008). Synthesis, characterization and antioxidant activity copper-quercetin complex. Journal of Molecular Structure, 892, 39-46. http://dx.doi.org/10.1016/j.saa.2008.07.030

[3] Card, H.C. \& Rhoderick, E.H. (1971). Studies of tunnel MOS diodes I. Interface effects in silicon Schottky diodes. Journal of Physics D: Applied Physics, 4(10), 1589-1601. http://dx.doi.org/10.1088/0022-3727/4/10/319

[4] Chaieb, A., Vignau, L., Brown, R., Wantz, G., Huby, N., François, J., \& Dagron-Lartigau, C. (2008). PL and EL properties of oligo(p-phenylene vinylene) (OPPV) derivatives and their applications in organic light-emitting diodes (OLED). Optical Materials, 31(1), 68-74. doi:http://dx.doi.org/10.1016/j.optmat.2008.01.012

[5] Chen, L., Deng, J., Gao, H., Yang, Q., Kong, L., Cui, M., Zhang, Z. (2016). Ellipsometric study and application of rubrene thin film in organic Schottky diode. Applied Surface Science, 388, 396400. http://dx.doi.org/10.1016/j.apsusc.2015.12.111

[6] Evyapan, M., Kadem, B., Basova, T. V., Yushina, I. V., \& Hassan, A. K. (2016). Study of the sensor response of spun metal phthalocyanine films to volatile organic vapors using surface plasmon resonance. Sensors and Actuators B: Chemical, 236, 605-613. doi:http://dx.doi.org/10.1016/j.snb.2016.05.070

[7] Haryanto, Wahyuningrum, D., \& Alni, A. (2015). Study on the Nitration Reaction of N,Ndiphenylamine Compounds and Its Characterization as Organic Light Emitting Diode (OLED) Material. Procedia Chemistry, 16, 586-591. doi:http://dx.doi.org/10.1016/j.proche.2015.12.096

[8] Güllü, Ö., Aydoğan, Ş., Türüt, A. (2012). High barrier Schottky diode with organic interlayer. Solid State Communications, 152 (5), 381-385 (2012). http://dx.doi.org/10.1016/j.ssc.2011.12.007

[9] Kösemen, Z. A., Kösemen, A., Öztürk, S., Canimkurbey, B., San, S. E., Yerli, Y., \& Tunç, A. V. (2016). Effect of intrinsic polymer properties on the photo sensitive organic field-effect transistors (Photo-OFETs). Microelectronic Engineering, 161, 36-42. doi:http://dx.doi.org/10.1016/j.mee.2016.04.007

[10] Lim, C. J., Li, L., Lei, Y., Zhou, F., Wu, B., Liu, X., . . Ng, S.-C. (2016). Synthesis and characterization of three thienopyridazine-based copolymers and their application in OFET. Tetrahedron Letters, 57(14), 1523-1527. doi:http://dx.doi.org/10.1016/j.tetlet.2016.02.049

[11] Nuhoğlu, Ç., \& Gülen, Y. (2010). The effect of high temperature annealing on Schottky diode characteristics of Au/n-Si contacts. Vacuum, 84 (6), 812-816. http://dx.doi.org/10.1016/j.vacuum.2009.10.049

[12] Norde, H. (1979). A modified forward I-V plot for Schottky diodes with high series resistance. J. Appl. Phys. 50, 5052. http://dx.doi.org/10.1063/1.325607 
[13] Ozaydin, C., Akkilic, K. (2014). Electrical and photoelectrical properties of copper(II) complex/n-Si/Au heterojunction diode. American Journal of Optics and Photonics, 2(6), 69-74. http://dx.doi.org/10.11648/j.ajop.20140206.11

[14] Ozerden, E., Yildiz, M., Ocak, Y. S., Tombak, A., \& Kilicoglu, T. (2014). An organicinorganic rectifying contact based on a $\mathrm{ZnPc}$ derivative. Materials Science in Semiconductor Processing, 28(0), 72-76. doi:http://dx.doi.org/10.1016/j.mssp.2014.06.006

[15] Remya, R., \& Deb, B. (2017). Ultrathin organic spin-on layers on indium tin oxide as a prospective tool for enhanced light throughput. Materials Letters, 186, 220-223. doi:http://dx.doi.org/10.1016/j.matlet.2016.10.008

[16] Sağlam, M., Cimilli, F. E., Türüt, A. (20049. Experimental determination of the laterally homogeneous barrier height of Au/n-Si Schottky barrier diodes. Physica B: Condensed Matter, 348 (1-4), 397-403. http://dx.doi.org/10.1016/j.physb.2004.01.002

[17] Shin, D., Lee, J.-Y., Hong, K.-Y., Park, J., \& Seo, Y.-S. Slot-die coating of organic thin films for active-matrix organic light-emitting diode displays. Thin Solid Films. doi:http://dx.doi.org/10.1016/j.tsf.2016.11.001

[18] Sung, M. J., Kim, Y., Lee, S. B., Lee, G. B., An, T. K., Cha, H., . . Kim, Y.-H. (2016). New dithienophosphole-based donor-acceptor alternating copolymers: Synthesis and structure property relationships in OFET. Dyes and Pigments, 125, 316-322. doi:http://dx.doi.org/10.1016/j.dyepig.2015.09.026

[19] Sze, S. M. \& Ng, K. K.. (2007). Physics of Semiconductor Devices. 3rd ed., 111 River St, Hoboken, 07030 New Jersey: John Wiley and Sons, Inc.

[20] Tombak, A., Ocak, Y. S., Asubay, S., Kilicoglu, T., \& Ozkahraman, F. (2014). Fabrication and electrical properties of an organic-inorganic device based on Coumarin 30 dye. Materials Science in Semiconductor Processing, 24, 187-192. doi:10.1016/j.mssp.2014.03.004 